\title{
Le mémoire de Mahelot, éd. crit. Pierre Pasquier
}

\section{Daniela Dalla Valle}

\section{(2) OpenEdition}

\section{Journals}

\section{Edizione digitale}

URL: http://journals.openedition.org/studifrancesi/30171

DOI: 10.4000/studifrancesi.30171

ISSN: 2421-5856

\section{Editore}

Rosenberg \& Sellier

\section{Edizione cartacea}

Data di pubblicazione: 1 avril 2006

Paginazione: 147

ISSN: 0039-2944

Notizia bibliografica digitale

Daniela Dalla Valle, «Le mémoire de Mahelot, éd. crit. Pierre Pasquier», Studi Francesi [Online], 148 (XLX

I) | 2006, online dal 30 novembre 2015, consultato il 18 avril 2021. URL: http://

journals.openedition.org/studifrancesi/30171 ; DOl: https://doi.org/10.4000/studifrancesi.30171

Questo documento è stato generato automaticamente il 18 avril 2021.

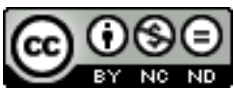

Studi Francesi è distribuita con Licenza Creative Commons Attribuzione - Non commerciale - Non opere derivate 4.0 Internazionale. 


\title{
Le mémoire de Mahelot, éd. crit. Pierre Pasquier
}

\author{
Daniela Dalla Valle
}

\section{NOTIZIA}

Le mémoire de Mahelot, éd. crit. Pierre Pasquier, Paris, Champion, 2005, pp. 371.

1 Dopo l'eccellente, ma ormai vecchia edizione di Henry Carrington Lancaster, pubblicata da Champion nel 1920, il famoso Mémoire è oggi ristampato presso lo stesso editore, a cura di Pierre Pasquier. Come il nuovo curatore precisa, l'edizione attuale non intende contrastare o correggere l'edizione precedente, ma si propone piuttosto d'inserire l'opera in una diversa conoscenza del teatro francese preclassico, che si è definita e precisata in questi ultimi decenni. Particolarmente interessante è quindi il lungo Avantpropos (pp. 7-197, più la bibliografia), con cui P. Pasquier presenta e analizza il Mémoire stesso. In questo studio, estremamente preciso e puntuale, ricchissimo di rinvii e di riferimenti, P. Pasquier si sofferma in primo luogo sul manoscritto stesso, s'interroga poi sulla funzione di un documento di questo tipo, sulla sua datazione e sui suoi redattori; dedica in seguito la sua attenzione all'Hôtel de Bourgogne e alla sua troupe, analizza le tecniche scenografiche nella prima metà del XVII secolo, distinguendo la scenografia all'Hôtel de Bourgogne da quella usata al Marais intorno agli anni 30, e conclude con un paragrafo dedicato alla scenografia classica all'Hôtel de Bourgogne e all'Hôtel Guénégaud.

2 Il Mémoire è poi riprodotto fedelmente (mentre l'edizione di Lancaster modernizzava la grafia). Non possiamo che essere grati a P. Pasquier per questa attenzione alla forma originale del testo, così difficile ormai nella riproduzione di opere secentesche. 